OAK RIDGE

NATIONAL LABORATORY

MANAGED BY UT-BATTELLE

FOR THE DEPARTMENT OF ENERGY

ORNL/TM-2004/187

Use of Electrochemical Noise to Assess Corrosion in Kraft Continuous Digesters

\title{
August 2004
}

S. J. Pawel

UT-BATTELLE 


\title{
DOCUMENT AVAILABILITY
}

Reports produced after January 1, 1996, are generally available free via the U.S. Department of Energy (DOE) Information Bridge.

Web site http://www.osti.gov/bridge

Reports produced before January 1, 1996, may be purchased by members of the public from the following source.

\author{
National Technical Information Service \\ 5285 Port Royal Road \\ Springfield, VA 22161 \\ Telephone 703-605-6000 (1-800-553-6847) \\ TDD 703-487-4639 \\ Fax 703-605-6900 \\ E-mailinfo@ntis.fedworld.gov \\ Web site http://www.ntis.gov/support/ordernowabout.htm
}

Reports are available to DOE employees, DOE contractors, Energy Technology Data Exchange (ETDE) representatives, and International Nuclear Information System (INIS)

representatives from the following source.

Office of Scientific and Technical Information

P.O. Box 62

Oak Ridge, TN 37831

Telephone 865-576-8401

Fax 865-576-5728

E-mail reports@adonis.osti.gov

Web site http://www.osti.gov/contact.html

This report was prepared as an account of work sponsored by an agency of the United States Government. Neither the United States Government nor any agency thereof, nor any of their employees, makes any warranty, express or implied, or assumes any legal liability or responsibility for the accuracy, completeness, or usefulness of any information, apparatus, product, or process disclosed, or represents that its use would not infringe privately owned rights. Reference herein to any specific commercial product, process, or service by trade name, trademark, manufacturer, or otherwise, does not necessarily constitute or imply its endorsement, recommendation, or favoring by the United States Government or any agency thereof. The views and opinions of authors expressed herein do not necessarily state or reflect those of the United States Government or any agency thereof. 
Metals and Ceramics Division

\title{
Use of Electrochemical Noise to Assess Corrosion in Kraft Continuous Digesters
}

\author{
S. J. Pawel
}

Date Published: August 2004

\author{
Prepared for the \\ U.S. Department of Energy \\ Assistant Secretary for Energy Efficiency and Renewable Energy \\ Office of Industrial Technologies \\ Forest and Paper Products Program \\ ED 1801010 \\ Prepared by \\ OAK RIDGE NATIONAL LABORATORY \\ Oak Ridge, Tennessee 37831-6285 \\ Operated by \\ UT-Battelle, LLC \\ for the \\ U. S. DEPARTMENT OF ENERGY \\ Under contract DE-AC05-00OR22725
}





\section{CONTENTS}

\section{Page}

TABLES $\ldots \ldots \ldots \ldots \ldots \ldots \ldots \ldots \ldots \ldots \ldots \ldots \ldots \ldots \ldots \ldots \ldots \ldots \ldots \ldots \ldots \ldots$

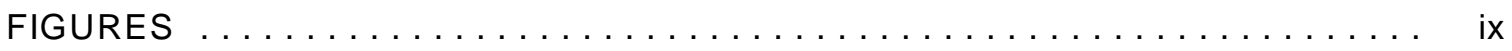

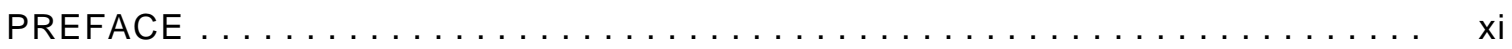

ABSTRACT $\ldots \ldots \ldots \ldots \ldots \ldots \ldots \ldots \ldots \ldots \ldots \ldots \ldots \ldots \ldots \ldots \ldots \ldots \ldots \ldots \ldots \ldots \ldots i i$

1. INTRODUCTION $\ldots \ldots \ldots \ldots \ldots \ldots \ldots \ldots \ldots \ldots \ldots \ldots \ldots \ldots \ldots \ldots \ldots$

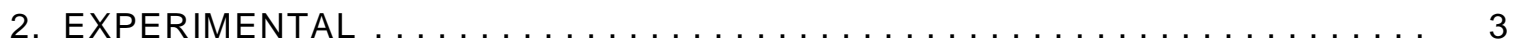

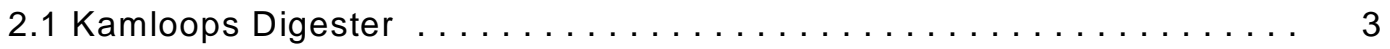

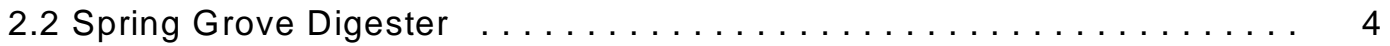

2.3 Data Collection Routine and Interpretation ............. 6

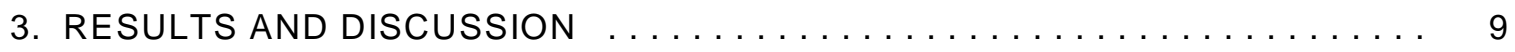

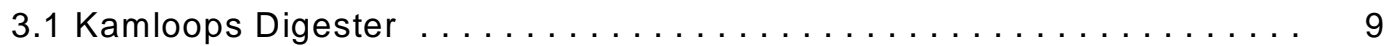

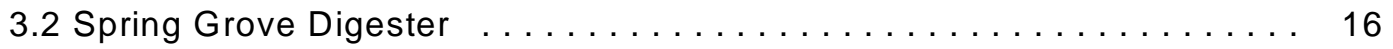

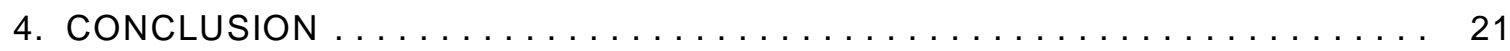

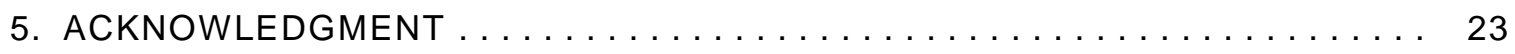

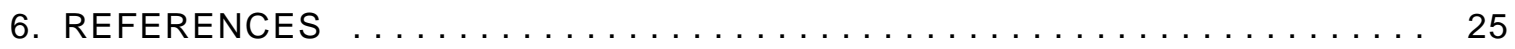





\section{TABLES}

Table

I. Composition of electrode materials used in the Spring Grove

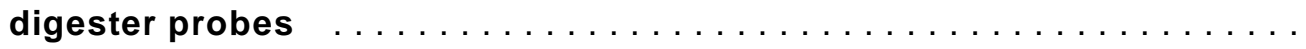

II. Comparison of constituents with the largest differences between whitewood and Douglas fir liquors from the full

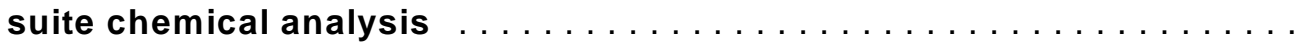

III. Average corrosion rates calculated for the digester shell compared with corrosion rate information available from the ECN probes 



\section{FIGURES}

$\begin{array}{ll}\text { Figure } & \text { Page }\end{array}$

1. Schematic of the Kamloops digester and probe placement, along with a probe photograph. The probe components are mounted in teflon - shown here are a pair of mild steel electrodes with a thermocouple and a silver reference. The probe diameter

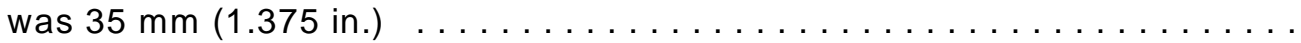

2. Schematic of the Spring Grove digester and probe placement, along with a probe photograph. The probe components are mounted in teflon - shown here are a pair of 309LSi stainless steel overlay electrodes and a pair of 312 stainless steel overlay electrodes and the silver reference electrode in the middle. The temperature measuring capability of this probe was a thermocouple welded to the inside of the stainless steel probe body about $7 \mathrm{~cm}$ behind the working face. The probe diameter was $38 \mathrm{~mm}(1.50 \mathrm{in}.) \ldots \ldots \ldots \ldots \ldots$

3. Representative EN data for Probe \#2 at Kamloops showing the variation in potential as a function of furnish composition

4. Representative EN data for Probe \#2 at Kamloops showing the variation in current (plotted in absolute value) as a function of furnish composition for the same period as shown in Fig. 3 



\section{PREFACE}

This document was originally published as part of the Proceedings of the TAPPI 2004 Spring Technical and International Environmental Conference (Paper Summit 2004), Atlanta, Georgia, May 2004. TAPPI is the Technical Association of the Pulp and Paper Industry.

This document represents the final report for the U.S. Department of Energy Office of Industrial Technologies entitled "Corrosion in Kraft Digesters." The paper was presented (and published as indicated above) in a DOE Peer Review Session at the TAPPI Conference. 



\begin{abstract}
Electrochemical noise (EN) probes were deployed in two continuous kraft digesters at a variety of locations representative of corrosion throughout the vessels. Current and potential noise, the temperature at each probe location, and the value of up to 60 process parameters (flow rates, liquor chemistry, etc.) were monitored continuously during each experiment. The results indicate that changes in furnish composition and process upsets were invariably associated with concurrent substantial changes in EN activity throughout the vessels. Post-test evaluation of the mild steel electrode materials in both vessels confirmed general corrosion of a magnitude consistent with historical trends in the respective vessels as well as values qualitatively (and semi-quantitatively) related to EN current sums for each electrode pair. Stainless steel electrodes representing 309LSi and 312 overlay repairs exhibited zero wastage corrosion - as did the actual overlays - but the EN data indicated periodic redox activity on the stainless steel that varied with time and position within the vessel. Little or no correlation between EN probe activity and other operational variables was observed in either vessel. Additional details for each digester experiment are summarized.
\end{abstract}





\section{INTRODUCTION}

Over the last decade, reports of high "out of experience" corrosion rates for mild steel digester vessels have become increasingly common. The trend appears to be applicable to relatively new vessels as well as older vessels that previously exhibited only modest corrosion rates. Coincident with observations of significantly increased corrosion, there have been a number of process changes in the industry mandated by environmental concerns, production goals, or energy requirements. Some of the changes which introduce uncertainties in process flow/chemistry include:

- modified cooking schemes,

- closed cycle chemistry and accumulation of non-process elements, and

- grade transitions to develop specific pulp properties and wood from new sources. In addition to these process changes, the recent spate of mills/companies changing ownership no doubt has increased surveillance and inspection intensity, which may indirectly account for increased observation of corrosion.

Historically, investigations of digester corrosion have utilized synthetic liquors prepared for use in laboratory coupon exposures. These tests have been instrumental in the identification of the influence(s) of some individual chemical constituents on the corrosion of digester construction materials. However, they suffer from the limitation that use of synthetic liquors does not allow for an assessment of the potential synergy among all the elements of the digester environment - the full suite of chemical constituents including organics as well as flow (liquor and chips), temperature variations, and other process factors. Even tests utilizing process liquor taken from operating digesters cannot fully simulate process factors, in part because liquors degrade rapidly upon contact with air and also because prior exposure at temperature (in the process) may influence subsequent corrosivity in the laboratory.

An alternate approach to evaluating digester corrosion has been the use of coupons of various types placed in operating digesters. These tests, too, have generated useful information but suffer from the limitation that the coupons can only be evaluated - for weight change, corrosion patterns, film formation, etc. - at extended intervals defined by the vessel maintenance/outage schedule (nominally one year). As a result, the coupons generate information about cumulative damage over the inspection interval but no information about specific conditions/times in which the corrosion process is active. Further, the coupons often cannot be placed such that they do not disturb the local flow patterns (e.g., are not flush-mounted with the digester wall). 
Largely due to its ability to monitor corrosion processes in real time, the electrochemical noise (EN) technique for monitoring corrosion is gaining acceptance in industrial applications. [References 1-5 are representative examples of many different field applications of EN presented at a recent symposium on the topic.] All corrosion processes (general and localized) cause spontaneous fluctuations of the free corrosion potential and current associated with corroding surfaces. These fluctuations, collectively termed EN, and the analysis thereof, can be used to assess corrosion processes. In a general sense, the magnitude, duration, and chronology of the EN transients, along with the potential at which these occur, can be used to determine whether the transients indicate general or localized (pitting or cracking) corrosion. ${ }^{6-7}$

In the EN technique, potential and current (and oftentimes temperature) are simultaneously measured. The current flow between two nominally identical coupled electrodes is monitored through a zero resistance ammeter. The corrosion potential of the couple is monitored with respect to a third electrode (reference) via a high impedance voltmeter. [Although the probe configuration could be used to generate polarization data, the standard EN technique does not impose an external potential that could disturb/disrupt passive film formation and the local chemistry.] This data, along with appropriate statistical manipulations and polarization information, can be used to assess the corrosion process form (general, pitting, cracking) and relative intensity during operations. Because instantaneous changes in corrosion activity can be determined, the EN technique can be used to identify changing process conditions giving rise to corrosion as it occurs.

The purpose of this document is to summarize selected data gathered during field deployment of EN probes in two continuous digesters. More complete and detailed reporting of the experiments and the EN data that were collected appears in Refs. 8-10. 


\section{EXPERIMENTAL}

\subsection{Kamloops Digester}

The Kamloops digester is a carbon steel Kamyr vessel commissioned in 1994 and operated in the continuous pulping mode. The vessel is approximately $52 \mathrm{~m}$ tall and the internal diameter varies from about $7 \mathrm{~m}$ at the top to $8 \mathrm{~m}$ at the bottom. With only minor variation in the process details, various modes of the Lo-Solids ${ }^{\mathrm{TM}}$ process to pulp combinations of pine, spruce, and Douglas fir have been consistently in use since about 2 months after start-up.

A schematic of the digester vessel appears in Fig. 1, along with the location of the five identical probes installed for this investigation. The probes were placed in ports originally constructed for the purpose of potential monitoring, which were roughly equi-spaced over the vertical dimension of the digester. The specific probe locations and design shell thickness at that location included:

Probe \#1: about $0.5 \mathrm{~m}$ below the top dome seam; $38 \mathrm{~mm}$ wall thickness,

Probe \#2: near the centerline of the trim screen locations; $39 \mathrm{~mm}$ wall thickness,

Probe \#3: about $0.5 \mathrm{~m}$ below the lower extraction screens; $46 \mathrm{~mm}$ wall thickness,

Probe \#4: about $0.5 \mathrm{~m}$ below the lower modified cooking screens; $53 \mathrm{~mm}$ wall thickness, and

Probe \#5: about $2 \mathrm{~m}$ below the wash screen; $58 \mathrm{~mm}$ wall thickness.

Because the ports for probe installation were built into the vessel at the time of original construction, the EN probes were designed to fit the available port diameter of $3.8 \mathrm{~cm}$ (1.5 in.). The probe configuration used for this investigation is also shown in Fig. 1. The two working electrodes were fabricated from rod stock of mild steel with a diameter of $0.95 \mathrm{~cm}$. The reference electrode was a silver rod, which upon exposure to the liquor/pulp environment establishes a reference potential based on the $\mathrm{Ag} / \mathrm{Ag}_{2} \mathrm{~S}$ pseudo-equilibrium. ${ }^{11}$ (It should be noted, however, that the long term use of $\mathrm{Ag}$ as a reference material in hot pulping liquors has been questioned. ${ }^{12}$ As no perfectly stable reference is known for industrial use in pulping liquors, only comparative statements relative to potentials are derived from the data presented here.) The thermocouple was a type-K variety in an alloy 600 sheath. All of the probe materials were mounted in a teflon shroud such that the working end of each was flush with the end of the shroud. The probe assembly was then mounted through a flanged port in the digester shell such that the working end of the probe was flush with the internal surface of the digester so as not to disturb localized flow and to represent the shell surface as well as possible. 


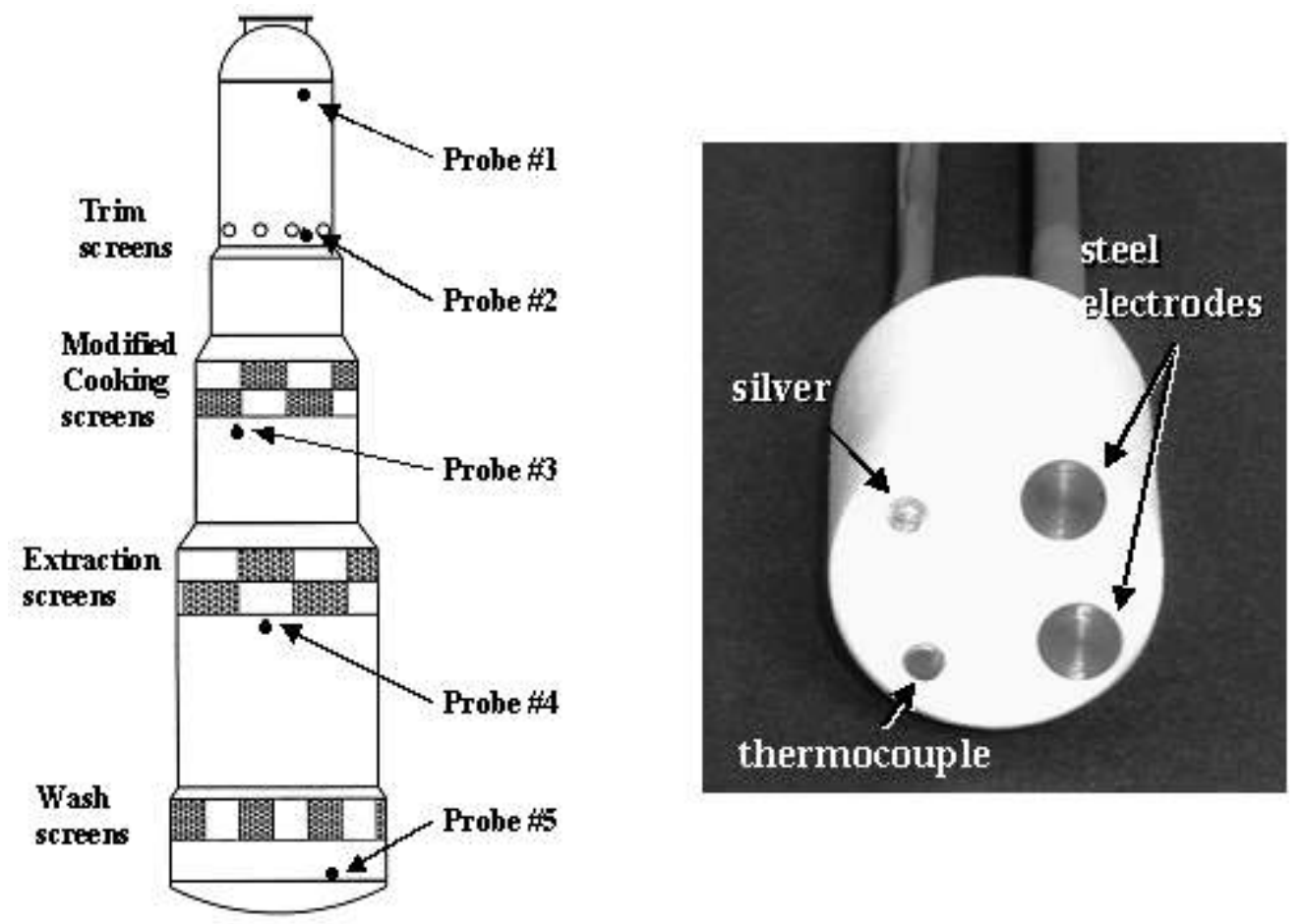

Fig. 1. Schematic of the Kamloops digester and probe placement, along with a probe photograph. The probe components are mounted in teflon - shown here are a pair of mild steel electrodes with a thermocouple and a silver reference. The probe diameter was $35 \mathrm{~mm}$ (1.375 in.).

\subsection{Spring Grove Digester}

This carbon steel Kamyr vessel is about $46 \mathrm{~m}$ tall and about $4 \mathrm{~m}$ wide at the bottom, and was commissioned in 1965 . The vessel has pulped exclusively pine species using conventional continuous cooking and, until recently, experienced relatively little corrosion/wastage problems. Coincident with a number of process changes in the last few years, however, general corrosion of the steel increased significantly, with average thinning rates at specific mid-vessel locations changing from less than $0.125 \mathrm{~mm} / \mathrm{y}$ ( $5 \mathrm{mils} / \mathrm{y}$ ) to in excess of $1 \mathrm{~mm} / \mathrm{y}$ (40 mils/y). In addition, just below the extraction screens in the vessel, general corrosion has varied significantly (more than a factor of two) on opposite sides of the vessel at the same elevation, indicating further unknown/unintended changes in local chemistry.

A schematic of the Spring Grove digester, probe locations, and representative probe appearance appears in Fig. 2. The probes in the Spring Grove vessel utilized dual electrode pairs, one representing the original mild steel construction and one representing the relatively new 309LSi stainless steel overlay in the vessel below the extraction screens, 
and were monitored simultaneously in the first year of the experiment. In the second year, the steel electrodes were replaced with type 312 stainless steel overlay electrodes to compare performance of the two stainless overlay compositions. Table I gives compositions for all the electrode materials. The specific probe locations and design shell thickness at that location included:

Probe \#12: about $2.5 \mathrm{~m}$ above top row of extraction screens; $36.5 \mathrm{~mm}$ wall thickness,

Probe \#6N: about 2 m below bottom row of extraction screens, above manway; $33 \mathrm{~mm}$ wall thickness,

Probe \#6S: same elevation as $6 \mathrm{~N}$, direct opposite side of the vessel; $33 \mathrm{~mm}$ wall thickness,

Probe \#3: about $2.5 \mathrm{~m}$ above top row of wash screens $(16 \mathrm{~m}) ; 34 \mathrm{~mm}$ wall thickness, and

Probe \#FT: in flash tank \#1, mid-slope in bottom cone $(2 \mathrm{~m}) ; 9.5 \mathrm{~mm}$ wall thickness.

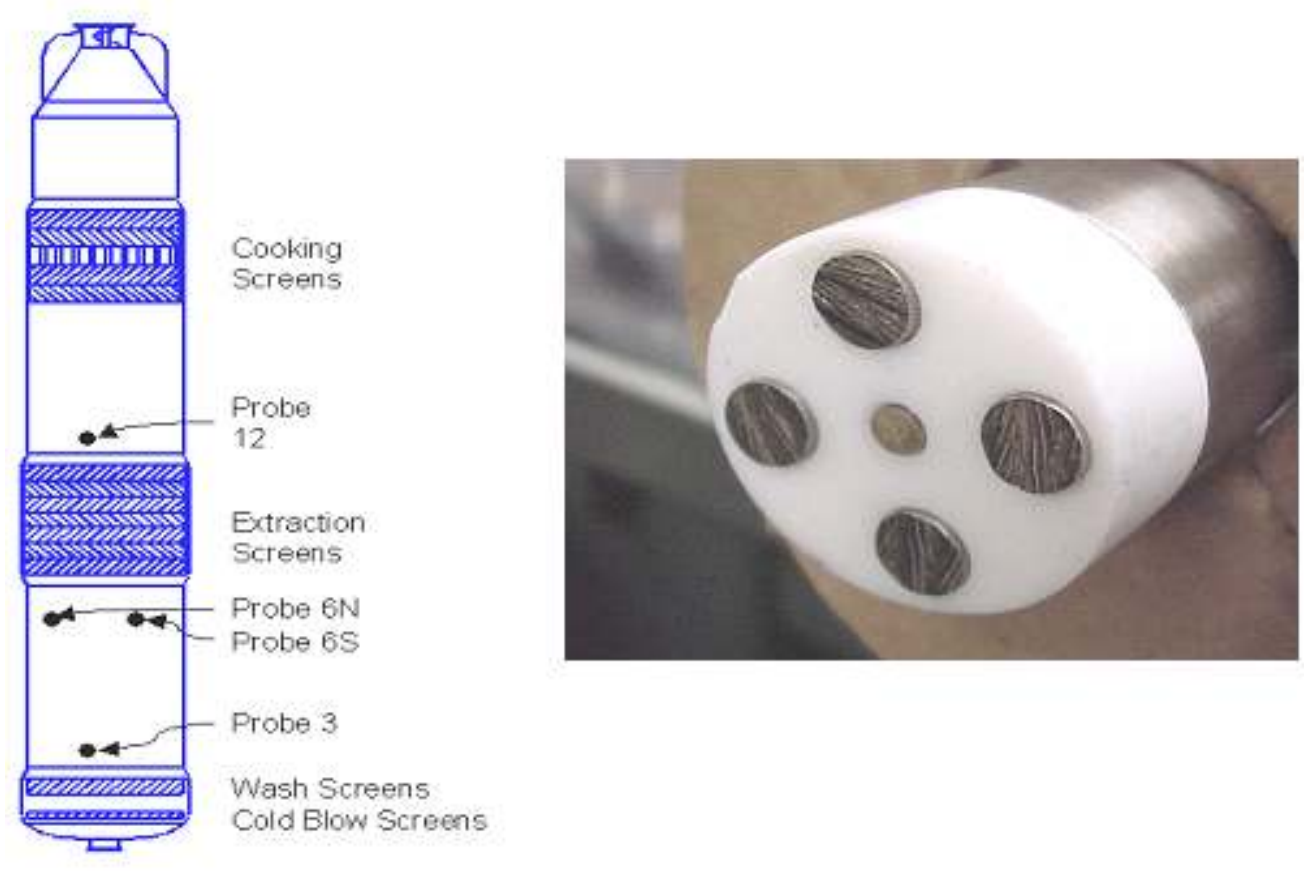

Fig. 2. Schematic of the Spring Grove digester and probe placement, along with a probe photograph. The probe components are mounted in teflon - shown here are a pair of 309LSi stainless steel overlay electrodes and a pair of 312 stainless steel overlay electrodes and the silver reference electrode in the middle. The temperature measuring capability of this probe was a thermocouple welded to the inside of the stainless steel probe body about $7 \mathrm{~cm}$ behind the working face. The probe diameter was $38 \mathrm{~mm}$ (1.50 in.). 
Table I. Composition of electrode materials used in the Spring Grove digester probes. The composition, given in weight percent, was determined from the average of nine determinations with an alloy analyzer. The ferrite number for the stainless steels was determined by an average of 20 determinations with a calibrated magnetic gage. No elements other than iron were detected with the alloy analyzer for the mild steel coupons, but a typical composition of A285-C mild steel is given for comparison.

\begin{tabular}{ccccc}
\hline Element & $\begin{array}{c}\text { Type 309LSi } \\
\text { electrode }\end{array}$ & $\begin{array}{c}\text { Type 309LSi } \\
\text { field overlay }\end{array}$ & $\begin{array}{c}\text { Type 312 } \\
\text { electrode }\end{array}$ & $\begin{array}{c}\text { Mild steel } \\
\text { electrode }\end{array}$ \\
\hline $\mathrm{Fe}$ & 57.9 & 63.6 & 60.3 & balance \\
$\mathrm{Cr}$ & 24.3 & 21.3 & 28.4 & 0.07 \\
$\mathrm{Ni}$ & 12.1 & 9.7 & 7.3 & 0.09 \\
$\mathrm{Mo}$ & 0.19 & 0.16 & 0.16 & 0.44 \\
$\mathrm{Mn}$ & 3.9 & 3.8 & 2.4 & \\
$\mathrm{~V}$ & 0.17 & 0.23 & 0.11 & 0.18 \\
$\mathrm{Ti}$ & 0.09 & & 0.06 & 0.19 \\
$\mathrm{Si}$ & & & & \\
$\mathrm{C}$ & 9 & 2 & 42 & \\
\hline
\end{tabular}

\subsection{Data Collection Routine and Interpretation}

Data collection from the probes in each digester commenced immediately following a major maintenance outage and continued, essentially uninterrupted, until the subsequent maintenance outage about one year later. At Kamloops, only one calendar year of experiments was conducted, while two consecutive years separated by a major maintenance outage were accomplished at Spring Grove.

Current and potential noise (one second intervals, $5 \mathrm{~min}$. rolling averages), the temperature at each probe location (one minute intervals), and the values of all the available process parameters (flow rates, liquor chemistry, pressures, etc. on intervals of 15-60 minutes, depending on the parameter) were monitored continuously for each experiment. Over the period of evaluation, the largest EN excursions were identified and a common feature (or group of features) among the available operating parameters was 
sought for correlation with the EN excursions. In addition, mathematical attempts via correlation coefficient analysis to relate process parameters and EN activity were also incorporated. The emphasis was, of course, to identify particular values (or ranges) of specific process parameters that correlate significantly with increased corrosion activity on at least one of the probes.

The value of current generated by the EN probes is a complex - and not necessarily straightforward - number. The current value in any sampling interval is the net current detected flowing through the zero-resistance ammeter (ZRA) connecting the nominally identical working electrodes and it typically oscillates at small magnitude in a largely random fashion about the value of zero. Depending on which electrode is momentarily active compared to the other electrode, current can flow from electrode $A$ toward electrode $B$ as well as in the opposite direction. As a result, EN current can be either "positive" or "negative" with - for the present discussion - no particular significance attached to the sign of the current flow. However, as the magnitude of the current activity is useful to compare events/conditions within the digester, it is sometimes convenient to plot the absolute value of the current activity during certain periods in order to facilitate comparisons.

The sums of absolute current over a specific period of time can be related - albeit in a somewhat crude fashion - to the corrosion rate experienced by the probes (and, in principle, the nearby digester wall). In order to develop such a relationship, certain simplifying assumptions are required. First, the total current must be consumed uniformly over the entire exposed surface area of each pair of electrodes. Essentially, this means that no localized corrosion - such as pitting or stress-corrosion cracking - is occurring (confirmed with post-test analysis of the electrodes in this experiment) and therefore current is related directly to thinning via general corrosion. In order to relate the current to mass loss and uniform thinning, it was assumed that the iron oxidizes from $\mathrm{Fe}$ to the $\mathrm{Fe}^{+2}$ state in all cases. Using these assumptions, the total current flow over any period can be related to corrosion rate via Faraday's Law. [See references 8-9 for further details.] Since not all the current for any reaction passes through the ZRA due to self-terminating circuits (anodes and cathodes on the same test electrode surface), and some amount of the current that does pass through the ZRA is related to redox reactions, the value so calculated essentially represents only a fraction, or a qualitative estimate, of the actual corrosion rate experienced by the probes (and nearby digester shell). 



\section{RESULTS AND DISCUSSION}

\subsection{Kamloops Digester}

The furnish to a digester is the wood chip mass that is introduced for pulping. The furnish composition is typically described by the fraction of each type of wood in the charge, which is usually set by a combination of desired pulp/paper properties, local types of available wood, and wood pile management at the particular mill. In the Kamloops digester, the nominal furnish is approximately $40 \%$ spruce, $40 \%$ pine, and $20 \%$ Douglas fir. To influence pulp/paper properties for specific products, two other furnish compositions are occasionally utilized at the mill. One is referred to as "whitewood," which is simply a mixture of roughly $50 \%$ spruce and $50 \%$ pine and the other is termed "Douglas fir," with a typical composition of $>70 \%$ Douglas fir with the remainder approximately equal amounts of spruce and pine.

Analysis of the EN data over the year-long experiment indicated that, among parameters for which data was available, furnish composition was the most significant operational variable influencing corrosion activity. ${ }^{8}$ Figure 3 is representative of the potential data associated with Probe-\#2 for all three furnish compositions. Note that the potential is fairly constant while pulping whitewood, slightly higher and somewhat more noisy (more spikes) while pulping the normal furnish, and increases about $60 \mathrm{mV}$ in stepfunction fashion when the furnish composition changes to Douglas fir. Based on analysis of polarization curves for steel in liquor taken from near this location, ${ }^{8}$ the increase in potential corresponds to a shift to near the active nose of a standard anodic curve and thus a shift to an increase in dissolution rate. The average potential at the other probe locations changes in a qualitatively similar fashion to that depicted in Fig. 3 - more noise and generally higher nominal potential - but Probe \#2 was selected for graphical representation because the background (white) noise in the potential data was so slight that the change in potential as a function of furnish composition is easy to display graphically.

Consistent with the potential data, Fig. 4 shows that the nominal current activity is very low during whitewood pulping, only modestly and irregularly higher during pulping of the normal furnish, but significantly higher during pulping of the furnish high in Douglas fir. Using the current summing concept previously mentioned, the solution generated while pulping Douglas fir is 1.5-4.0 times more corrosive to mild steel than the solution generated while pulping the normal furnish, which is generally $20-50 \%$ more corrosive than the solution generated pulping whitewood. ${ }^{8}$ Clearly, this is not an absolute number, because the manner of calculation assumes that increased corrosion activity detected by the ZRA 


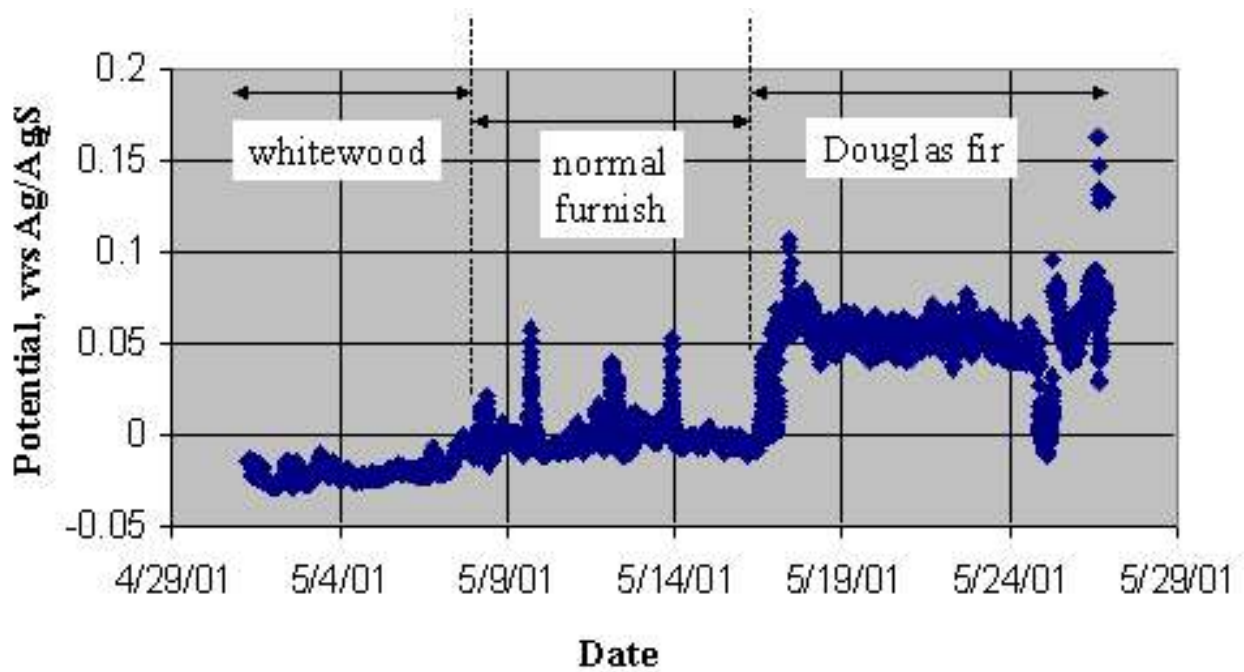

Fig. 3. Representative EN data for Probe \#2 at Kamloops showing the variation in potential as a function of furnish composition.

corresponds in some regular fashion to corrosion of the steel (as opposed to current associated with redox reactions, for example) and that this comparison is valid under different pulping conditions. However, because the background noise of the process seems to remain relatively constant and the corrosion activity on each probe was determined to be only general corrosion (using complementary polarization curves and post-test evaluation), the correlation of corrosivities appears to have at least semi-quantitative merit.

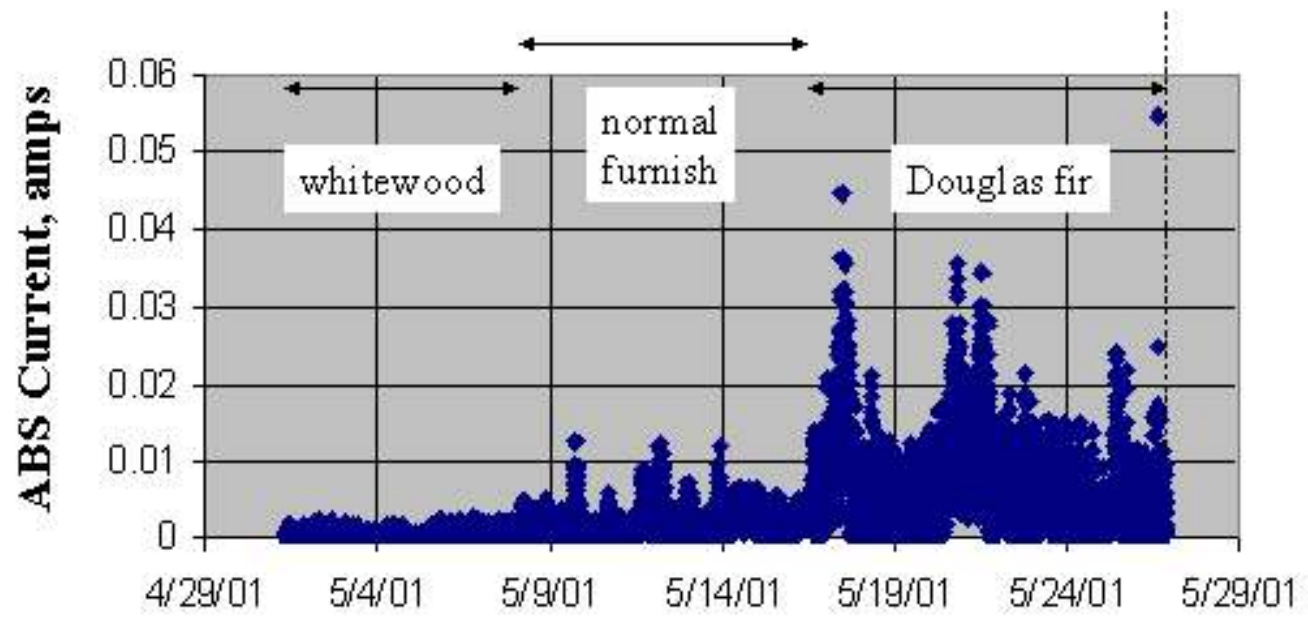

Date

Fig. 4. Representative EN data for Probe \#2 at Kamloops showing the variation in current (plotted in absolute value) as a function of furnish composition for the same period as shown in Fig. 3. 
Liquors sampled during Douglas fir and whitewood pulping were extensively analyzed in an effort to identify compositional differences that might account for the observed variations in EN activity on steel electrodes as a function of furnish composition. Liquor was collected from three locations (upper extraction, upper modified cooking, and bottom circulation) and sampled twice (day one and day five) during the respective pulping runs. The results (including duplicate analyses that showed excellent agreement) are too numerous to individually list ${ }^{13}$ but some general trends can be identified. For example, the metals content of the whitewood and Douglas fir liquors are remarkably similar, with only $\mathrm{Na}$ and $\mathrm{K}$ showing more than negligible variation among 29 metals in the analysis - in this case, both constituents are higher in whitewood liquor by about 10\% (corresponding to a 2-3000 ppm difference). Among the standard inorganic analyses, it was noted that the $\mathrm{pH}$ of the Douglas for liquor was routinely 0.3 higher than for equivalent whitewood sampling, but the hydroxide content of the black liquor was an average of about $10 \%$ higher (corresponding to 1-2000 ppm variation) in the whitewood. Sulfite, acetate, and butyrate were all higher in the Douglas fir liquor by as much as about $100 \%$ (but corresponding to a variation of only a few hundred ppm). Similarly, sulfide was higher in Douglas fir pulping than whitewood by about $20 \%$, but some of that difference is an intentional adjustment in the white liquor charge to the digester to compensate for the change in wood species. Analysis for a total of 21 specific extractives (catechols, resin acids, etc.) was included in the effort, but the whitewood and Douglas fir liquors were largely indistinguishable in this regard. Table II lists the three numerically largest differences in extractive content between the two liquors - in all three cases, Douglas fir contained $100-300 \%$ more of the constituent in question, but the variations correspond to only $250-400 \mathrm{ppm}$ difference. Analysis for a total of 20 specific hydrocarboxylic acids was also included, and there were several constituents identified (also listed in Table II) with concentration differences between whitewood and Douglas fir as large as 100-1000\%, but note that the Douglas fir liquor does not always exhibit the higher concentration among these constituents. Clearly, to distinguish or isolate a specific constituent among the many possible synergies of liquor chemistry is a quite daunting task. 
Table II. Comparison of constituents with the largest differences between whitewood and Douglas fir liquors from the full suite chemical analysis.

\begin{tabular}{llll}
\hline \multicolumn{1}{c}{ Extractive constituent } & Greater in & By $\%$ & By ppm \\
\hline 4-hydroxy 3-methyoxylbenzaldehyde & Douglas fir & to 120\% & to $300 \mathrm{ppm}$ \\
4-hydroxy 3-methyoxyacetophenone & Douglas fir & to $90 \%$ & to $250 \mathrm{ppm}$ \\
3-(4-hydroxy 3-methoxyphenyl) propanol & Douglas fir & to 300\% & to $400 \mathrm{ppm}$ \\
\hline \multicolumn{1}{c}{ Hydorcarboxylic acid constituent } & & & \\
\hline 2,3-bideoxypentaric acid & Douglas fir & to 1300\% & to $5800 \mathrm{ppm}$ \\
3-hydroxy 3,5-dicarboxyfurane & Douglas fir & to $300 \%$ & to $900 \mathrm{ppm}$ \\
hexonic acid & Douglas fir & to $300 \%$ & to $6000 \mathrm{ppm}$ \\
2-hydroxy 2-methylhydroxybutyric acid & whitewood & to $95 \%$ & to $3200 \mathrm{ppm}$ \\
3-deoxy 2,5-bihydroxy 2-methylhydroxypentonic acid & whitewood & to $96 \%$ & to $5100 \mathrm{ppm}$ \\
2,5-bihydroxypentonic acid (lactone) & whitewood & to $78 \%$ & to $600 \mathrm{ppm}$ \\
\hline
\end{tabular}

It has been known for some time that 1,2-dihydroxybenzene constituents and related $\alpha$-hydroxy acids, such as catechols and their derivatives, could be responsible for the observed increase in steel corrosion activity during Douglas fir pulping. These compounds are capable of functioning as a stable complexing agent for steel in strong alkaline solutions, which tends to decrease local activity of iron (remove iron ions from solution) and thereby inhibit iron ions from participation in the formation of passive films. As early as 1953, increased corrosion of steel as a result of taxifolin (a heartwood component of Douglas fir) and similar catechol derivatives was identified, ${ }^{14}$ and more recent efforts at the Institute of Paper Science and Technology ${ }^{15}$ seem to confirm the aggressive nature of catechols/taxifolin in alkaline pulping liquors toward steel. While the analytical work described above on the Kamloops digester liquors did not identify a particular constituent responsible for increased corrosion of steel - and, in fact, six specific catechol species were found to be notably absent from all the liquor samples - the general results seem to confirm the possibility that complex organic constituents outside the suite included in nominal mill analyses are largely responsible for increased corrosion in Douglas fir pulp.

Probe \#2 revealed changes in current and potential associated with furnish changes at times corresponding precisely to those indicated in the operator's log for the digester (no time delay between furnish change and ECN response at Probe \#2). Although there is 
more general scatter and background noise in the data for the other probes further down the digester, it is nevertheless clear that all probes indicate generally similar (but perhaps less dramatic) responses to furnish composition within a very brief time of the furnish changes introduced into the vessel. The precise onset of a change in current/potential activity for each probe associated with furnish compositions high in Douglas fir is difficult to determine, but it is clear from the data that the change is relatively rapid (minutes to about an hour) rather than the several hours required for the slug of wood chip mass to move from the top of the vessel to sequentially lower probe positions in the digester. This result suggests that transport of corrosive constituents within the digester is more rapid than previously thought and apparently occurs via communication in the liquor as opposed to the wood chip mass. This result is somewhat consistent with one of the preliminary results of an effort to model the near-wall flow and chemistry in the digester. ${ }^{16}$ In the modeling effort, the possibility of the presence of a clear layer - a relatively thin boundary layer of liquor with no chips - immediately adjacent to the digester walls presents itself. While little is known about the physical reality of such speculation, it seems intuitive that the presence of a clear layer would enable relatively rapid communication of liquor chemistry along the vessel walls.

Generally speaking, the largest effect of Douglas fir was observed at the position of Probe \#2, and the effect decreased with distance down the digester. This observation is potentially consistent with a complexing mechanism for increased corrosion. As the Douglas fir is admitted to the top of the vessel along with the liquor charge, the pulping reaction is initiated. After a short amount of time (less than the time required for the chip mass to move from the top of the vessel to near the Probe \#2 position), the chemical reaction generating the catechols (complexing agent) is at a maximum because the reaction between fresh chips and strong liquor produces the most leachate at this location. As the liquor/chip mass moves through the digester, the generation rate of catechols is exceeded by the rate at which they are consumed, so that the effect of the catechols and, thus, the influence of Douglas fir, becomes relatively less lower in the vessel. This is not to imply that the total corrosion activity becomes smaller as the chip mass moves through/down the vessel, just that the relative influence of the Douglas fir becomes less with position down the vessel. Furthermore, there is generally upflow of liquor in the bottom half of the vessel (below the extraction screens, set by the specific liquor recirculation pattern), and this may have the effect of diluting the aggressive chemicals in the lower half of the vessel. This would decrease the contribution of Douglas fir constituents to corrosion at lower levels in the digester. 
As a general trend observed in this experiment, the increased corrosion activity associated with a high fraction of Douglas fir in the furnish tends to have a larger impact on corrosion at the onset of the change to Douglas fir than after several days of the more aggressive furnish. The reason(s) for this behavior are not clear from the data collected here, but perhaps the steel is able to respond to the more aggressive furnish by corroding to an extent that passivation becomes possible.

A correlation coefficient analysis was performed for all combinations of EN data and operational values for instantaneous correlation as well as delay times in 15-minute intervals up to two hours (to account for the potential lag time between an adjustment to a parameter and the response in the vessel). However, with the exception of furnish composition, no significant correlation was found between any other measured/tracked process parameters and corrosion activity at Kamloops. There are several potential explanations for the apparent absence of correlations. In a general sense, this result may indicate that possible correlations are non-linear or multi-variable rather than simple linear relationships. Such complex relationships, at best, are difficult to detect in a large array of variables, particularly when there are no known outcomes on which to model non-linear relationships. Related to possible non-linearity, there may be so little variation in the process parameters with time (tight process control aimed at a precise kappa number or other process goal) that the establishment of any strong correlation among process parameters and corrosion is impractical. Finally, it is possible that the collected process data simply has little or no relationship to vessel corrosion.

It should be noted that a few operational variables, such as production rate and residual alkali, were found to exhibit slight variations from the normal values coincident with changes in furnish composition and corrosion activity. ${ }^{8}$ While each of these may contribute a small portion to the entire observed effect of Douglas fir pulping, each of these parameters are changed slightly - but intentionally - to facilitate Douglas fir pulping. As a result, these are not independent parameters in the strictest sense. Further, brief changes in these values do not seem to correlate with increased corrosion activity unless there is a coincident change to a more aggressive furnish. As a result, the aggressive furnish is considered to be the independent variable and the parameter of greatest significance for vessel corrosion.

Following the year-long exposure, the probes were removed from the digester for evaluation. [The reader is again referred to Ref. 8 for details regarding the full analysis of the electrodes.] The electrodes from each probe were examined in the as-corroded condition following the test and found to have relatively uniform corrosion product accumulation and coloration patterns common to general corrosion. No pits or signs of 
crevice corrosion (for example, on the electrode surfaces nominally against the teflon shroud) were apparent on any of the electrodes, which is consistent with the EN signals and polarization data collected.

After the initial examination, the electrode specimens were cleaned in inhibited hydrochloric acid per the standard practice of ASTM G-1 (Procedure C.3.5) to remove the corrosion products without incurring further corrosion on the specimens. The cleaning procedure did not reveal any signs of significant localized corrosion on any of the electrodes, only a slightly mottled appearance common to general corrosion processes. The exposed circular faces of Probe \#3 electrodes appeared almost polished, indicating a rather high general corrosion rate, as did some portion of the cylindrical sides that became exposed as the specimens corroded during the test.

In the cleaned condition, the post-test dimensions of the electrodes were recorded for comparison with initial dimensions. Using a total exposure time of 49 weeks and the fact that corrosion on the diameter occurs from two directions while corrosion on the specimen length occurs in only one, the average annual corrosion rate for the electrodes at each probe position was calculated. Table III compares the average corrosion rates determined from ultrasonic thickness measurements on the vessel wall near the probe locations with corrosion rates estimated from the EN signals and the actual corrosion damage to the electrodes during the test. Given the inability of the current summing technique to precisely predict general corrosion rates, the agreement between these different assessments is quite good. It is not clear if the corrosion rates predicted by the EN probes decrease over the exposure period due to passivation of the probe surfaces or an actual decrease in the average corrosivity of the environment.

Table III. Average corrosion rates calculated for the digester shell compared with corrosion rate information available from the ECN probes. The historical rates given were determined from ultrasonic testing (UT) of the wall thickness in areas near the probe locations. Corrosion rates are given in $\mathrm{mm} / \mathrm{y}$. To convert to mils/y, multiply the numbers in the table by 39.37 .

\begin{tabular}{llllll}
\hline & Probe \#1 & Probe \#2 & Probe \#3 & Probe \#4 & Probe \#5 \\
\cline { 2 - 6 } Historical average (UT) & $0.13-0.20$ & $0.18-0.25$ & $0.25-0.31$ & $0.18-0.25$ & $0.03-0.05$ \\
Probe assessment (examination & $0.03-0.05$ & $0.25-0.31$ & $0.41-0.43$ & $0.18-0.20$ & $<0.03$ \\
Integrated current (1 ${ }^{\text {st }}$ six months) & 0.13 & 0.13 & 0.31 & 0.18 & 0.05 \\
Integrated current (full 12 months) & 0.08 & 0.10 & 0.18 & 0.13 & 0.03 \\
\hline
\end{tabular}


It is also clear from the limited EN data collected during shutdown and startup transients that these events are quite significant in terms of total corrosion activity. The reader is referred to Ref. 8 for details, but it should be noted that the same current sum technique as that presented here indicates the relative corrosion rate during these transients may be approximately 20 times that during nominal operation. [Some of the current activity associated with shut-down and start-up is no doubt a result of redox reactions that do not contribute directly to wastage.] The reasons are not clear from this experiment, but in the particular case of this vessel, the residual black liquor on the walls during downtime may react with air to form thiosulfates, which are quite corrosive toward steel.

\subsection{Spring Grove Digester}

The corrosion data derived from the ECN probes at Spring Grove indicated very high corrosion rates for steel at several probe positions but essentially nil corrosion on the stainless steel overlay electrodes. ${ }^{9-10}$ Summary information from the analysis of the Spring Grove probes appears in the paragraphs that follow.

Based on post-test examination of the electrodes in year \#1, the steel from probe $6 \mathrm{~N}$ exhibited general corrosion at a rate of $2.2 \mathrm{~mm} / \mathrm{y}$ ( $85 \mathrm{mils} / \mathrm{y})$ while the steel electrodes at the same elevation but directly across the vessel at probe $6 \mathrm{~S}$ exhibited general corrosion at a rate of $1.3 \mathrm{~mm} / \mathrm{y}$ (5 mils/y). These corrosion rates are considerably higher than expected based on recent historical wall thinning data at ring 6 . However, the result is consistent with the observation that thinning on the $6 \mathrm{~N}$ side of the vessel has outpaced that on the $6 \mathrm{~S}$ side by more than $2.5 \mathrm{~mm}$ (100 mils) over the last few years. Calculated wastage rates for the steel electrodes of probes $6 \mathrm{~N}$ and $6 \mathrm{~S}$ - using current sums - were lower than the actual measured values by a factor of $6-8(0.55$ and $0.24 \mathrm{~mm} / \mathrm{y}$, respectively). At such extreme general corrosion rates, it is not a surprise that the current sum estimates of corrosion rate would underestimate the actual values because high general corrosion rates suggest closely spaced (and frequently forming/disappearing) anodes and cathodes with corresponding high fractions of self-terminating current upon each electrode. In comparison, the lower general corrosion rates of steel in the Kamloops digester may tend to minimize the self-terminating current fraction of the total, and therefore the current sums estimates are closer to actual wastage values. Curiously, the temperature at probe $6 S$ (lower corrosion rate) was routinely $10-15^{\circ} \mathrm{C}$ higher than that at the probe $6 \mathrm{~N}$ position. Since aqueous corrosion generally increases significantly with increased temperature, this result suggests a significant composition gradient in the liquor at this elevation in the vessel. 
It may also imply a decrease in the rate or efficiency of a complexing agent for iron at higher temperatures.

The steel at ring 3 also exhibited a significantly higher actual wastage compared with the current sum for the period, while current sums for the steel at ring 12 and in the flash tank corresponded very well with actual corrosion rates determined from physical examination of the post-test electrodes. That the actual corrosion rates exhibited by the steel electrodes from probes $6 \mathrm{~N}, 6 \mathrm{~S}$, and 3 were considerably higher than historical rates at corresponding positions in the vessel suggests that the recent trend of high corrosion rates for steel is continuing or even accelerating.

The 309LSi stainless steel overlay applied to the vessel shell on rings 5 and 6 (upper half of the vessel between the extraction and wash screens) just prior to this probe installation performed exceptionally well, exhibiting no evidence of general wastage or pitting. Consistent with the observed performance of the 309LSi overlay, none of the 309LSi stainless steel electrodes in the digester or flash tank revealed any evidence of corrosion. In the second year, type 312 overlay electrodes also revealed essentially nil corrosion. However, the current sums generated from the EN data indicate variable degrees of corrosion activity. In particular, the stainless steel electrodes at ring $6 \mathrm{~S}$ and ring 3 consistently exhibited an order of magnitude greater current activity in year \#1 than their counterparts at ring $6 \mathrm{~N}$ and ring 12. Significant EN current activity in the absence of corrosion indicates that redox reactions rather than wastage reactions are dominating the noise measurements. All electrodes (stainless steel and carbon steel) exhibited noise resistance values much too low for the observed corrosion rates, again suggesting that the EN calculation of noise resistance is dominated by the high frequency redox reactions in the Spring Grove digester. A potential improvement in probe design would incorporate the capability to distinguish redox and wastage components of the EN signals.

Attempts to correlate changes in EN corrosion activity with changes in individual process parameters that are tracked by the Spring Grove mill were not successful. Aside from start-up and shutdown transients, including somewhat regular upsets in the vessel in which most/all of the process parameters deviate significantly from nominal set points for a brief period, no individual process parameters correlated significantly with EN activity. (All linear correlation coefficients between an EN parameter and a process variable were less than 0.66 , and most were considerably lower). These operational transients are aggressive corrosion events but generally are relatively short-lived in the scope of overall service duty. Further, no individual process change such as the introduction of oxygen delignification (in 1994) could be associated in a specific way with accelerated corrosion of the steel vessel. 
Attempts to find such correlations ${ }^{17}$ are complicated by the fact that process parameters rarely change in isolation from other variables, and that many of the variables that are tracked are for the purpose of generating product with particular properties as opposed to understanding corrosion in the vessel.

By comparing present visual inspection data with similar information from the recent past, ${ }^{9-10}$ it is clear that corrosion conditions aggressive to mild steel persist in the Spring Grove digester. In the June 2003 inspection, localized corrosion of mild steel surfaces was observed in locations previously free of attack such as near the top of the vessel and below the wash screens. Further, there was evidence that the depth of localized attack increased in some positions during the prior year. Nevertheless, the type 309LSi overlay material appears essentially immune to attack after two years of service, as evidenced by it's near pristine appearance, including residual slight surface relief and heat tint resulting from the original deposition process. Consistent with this observation, the electrodes of 309LSi stainless steel in each probe also exhibited no attack during the year \#2 exposure. Very slight interdendritic attack - insignificant in a practical sense - was observed on the type 312 stainless steel electrodes from all the probes in year \#2. It should be noted that despite similar resistance to the process solution, current sums (and potential transients) for the $309 \mathrm{LSi}$ and 312 electrodes on the same probe varied periodically, indicating that the passive films of these materials do not respond equivalently to (i.e., are not equally supportive of) some of the reactions that occur on the surface.

The general results from the EN experiments at Spring Grove remain somewhat inconclusive. By comparing current and potential noise activity from the probes on opposite sides of the vessel at the ring 6 elevation, it is clear that environmental conditions (chemistry, flow, temperature) can vary in ways that are not incorporated by various predictive models that depend upon circumferential symmetry. For example, the temperature gradient at this location in year \#2 was substantially different than for the prior year, suggesting flow and mixing in the digester changed. In addition, potential excursions occur for the stainless steel electrodes on one side of the vessel and not the other, and also exhibit different excursion tendencies in response to the same event. This may indicate the possibility of periodic gradients/changes in the local chemistry within the vessel. Further, current sums vary regularly on opposite sides of the vessel and, since no wastage was observed on the electrodes, this indicates that redox chemistry/conditions vary by a significant amount on a consistent basis. These environmental variations no doubt could contribute to corrosion of the vessel, but inability to identify specific chemical constituents 
associated with the ECN transients limits assessment of the corrosion conditions in the vessel.

The silver electrodes in the Spring Grove probes revealed various degrees of reaction to silver sulfide during the year-long exposure, but since some amount of silver remained in contact with silver sulfide throughout each experiment, it appears the silver performed as a suitable (pseudo) reference. However, the observation of a highly variable extent of transition of $\mathrm{Ag}$ to $\mathrm{Ag}_{2} \mathrm{~S}$, even at opposite sides of the vessel at ring 6 and in consecutive years, is further evidence of the highly variable local chemistry and temperature in the vessel that is not detected by standard mill analyses.

Mild steel test panels exposed in the Spring Grove digester near the extraction screens to examine the role of mill scale in the observed localized corrosion pattern revealed little or no influence of simulated oxides on the total corrosion/erosion or wastage patterns. ${ }^{10}$ All of the mild steel panels suffered significant general thinning, but extensive wastage along the leading (flow-facing) corners/edges - but not under the teflon shoulder washers - indicated a significant component of erosion on material at this location near the extraction screens. Concurrent laboratory autoclave testing ${ }^{10}$ of the same steel/oxide specimens in simulated pulping liquors indicated some benefit of oxide scales for reducing corrosion rate - particularly in simulated extraction liquors - but the effect was not particularly reproducible. Partial coverage of coupons with an oxide film - intended to simulate possible galvanic effects at regions where scale had been ground/removed - was not a significant factor in the autoclave test results. Type $304 \mathrm{~L}$ stainless steel test panels from the digester were essentially immune to attack, as were similar coupons in the autoclave tests with simulated extraction liquors. However, the stainless steel coupons exposed to simulated white liquor in the autoclave revealed some tendency to cracking. 


\section{CONCLUSION}

To the knowledge of the author, these probe installations were the first-of-a-kind effort to bring EN corrosion monitoring technology into an operating digester. The equipment and probes functioned successfully throughout the total of three year-long experiments with no failures or disruptions to mill operations.

At Kamloops, the EN current sums from each pair of steel electrodes were found to be qualitatively consistent with corrosion rates in the digester at each probe position and with actual electrode wastage, and the quantitative calculations of corrosion rate generated by the probes were reasonably accurate. At Spring Grove, however, where the steel corrosion rates were generally much higher than at Kamloops, the ECN current sums underestimated actual wastage by a factor of $6-8$ at some probe positions. The qualitative ranking of relative corrosion rates, however, was good.

Using the integrated current sum technique, operation with furnish compositions high in Douglas fir (Kamloops) and shutdown periods (both digesters) were identified as particularly aggressive corrosion events. At Kamloops, corrosion activity at each probe location increased sharply with changes from whitewood or normal furnish to Douglas fir furnish, and the effect was most pronounced relatively high in the digester (near the trim screens). As indicated by the results from the initial attempt, full chemical analysis of the pulp liquors to identify the species responsible for increased corrosion of steel as a function of furnish composition is likely to be a daunting task. All probes in the Kamloops digester tended to respond to changes in furnish composition within minutes to an hour, possibly through a "clear layer" of liquor adjacent to the vessel walls that accelerates chemical communication.

Corrosion probe activity did not correlate linearly with any of the operational/process variables that are routinely tracked at either mill. This result implies that the relationships between operating variables and corrosion are complex (e.g., non-linear or multivariate) or that the data most relevant to digester corrosion is not being collected. In addition, the fact that chemical control feedback loops have been established to tightly restrict process variations limits the ability to identify cause/effect relationships (or correlations) in the operation.

Consistent with the performance of the actual repair overlay, the 309LSi and 312 overlay electrodes in the probes at Spring Grove were essentially immune to wastage (corrosion or erosion) during the period of exposure. Current sums reveal variable redox reactions occurring on the probes, and the persistence of differences in redox activity as a 
function of position in the digester suggest liquor chemistry gradients that are not detected by routine chemical analysis. In addition, variable response (EN excursions) to process upsets as a function of position, particularly on opposite sides of the vessel at the ring 6 elevation, suggest routine (but unknown or under-appreciated) variations in liquor chemistry or flow dominate the corrosion activity at these locations in the vessel. Further, such asymmetric variations appear to be inconsistent with present modeling efforts. 


\section{Acknowledgment}

This research was funded by the U.S. Department of Energy Office of Industrial Technologies for the Agenda 2020 Forest Products Program. The Oak Ridge National Laboratory (ORNL) Program Manager for this effort was $P$. Angelini. The industrial advisory board consisted of M. E. Gorog (Weyerhaeuser), W.B.A. Sharp and S. J. Lukezich (MeadWestvaco), and D. C. Crowe (International Paper), M. Gregson, M. Gorog, K. Robarge, and J. Gancas (all of Weyerhaeuser) were instrumental in arranging field support services at the Kamloops pulp mill to facilitate probe installation, data gathering, and information exchange. D. Roy, H. Muller, R. Able, and T. Redding (all of Glatfelter) performed similar roles at the Spring Grove mill. J. McKee (Corrosion and Condition Control, Ltd.) was helpful in data collection and transfer efforts from the data collection system. D. W. Townley (M. J. Schiff and Associates) participated in system design, data collection and analysis, participated in many helpful discussions. D. A. Singbeil and N. J. Stead (Paprican) provided probe design support and fabrication, as did C. Moore (Rohrback Cosasco Systems). P. Singh (IPST) facilitated chemical analysis efforts and provided technical discussions and support. E. T. Manneschmidt and K. A. Choudhury (ORNL) provided computer graphics/image file support; J. R. Keiser and D. F. Wilson (ORNL) provided technical support and reviewed this manuscript, and F. Stooksbury final preparation of the manuscript. 



\section{REFERENCES}

1. M. Amaya, et. al., "Electrochemical Noise in Assessing MIC in Offshore Injection Systems," CORROSION 2001, paper no. 01269, NACE, Houston, TX, March 2001.

2. E. E. Barr, A. H. Greenfield, and L. Pierrard, "Application of Electrochemical Noise Monitoring to Inhibitor Evaluation and Optimization in the Field: Results from the Kaybob South Sour Gas Field," CORROSION 2001, paper no. 01288, NACE, Houston, TX, March 2001.

3. G. L. Edgemon, "Electrochemical Noise Based Corrosion Monitoring at the Hanford Site: Third Generation System Development, Design, and Data," CORROSION 2001, paper no. 01282, NACE, Houston, TX, March 2001.

4. D. Townley and S. J. Duranceau, "Instrumentation Considerations for Electrochemical Noise Corrosion Monitoring in the Field," CORROSION 2001, paper no. 01287, NACE, Houston, TX, March 2001.

5. G. P. Quirk, D. A. Eden, and R. J. Jacko, "Secondary Side SCC of Alloy 600 in Occluded TSP Crevices - Development of an Electrochemical Noise Probe for Plant Installation," CORROSION 2001, paper no. 01123, NACE, Houston, TX, March 2001.

6. U. Bertocci, "Electrochemical Noise Analysis and its Application to Corrosion," CORROSION 1989, paper no. 24, NACE, New Orleans, LA, April 1989.

7. J. L. Dawson, et. al., "Corrosion Monitoring Using Electrochemical Noise Measurements," CORROSION 1989, paper no. 31, NACE, New Orleans, LA, April 1989.

8. S. J. Pawel, D. W. Townley, M. E. Gorog, and D. F. Wilson, Correlation of Process Data and Electrochemical Noise to Assess Kraft Digester Corrosion: Kamloops Experiment, Oak Ridge National Laboratory Technical Memo ORNL/TM-2002/33, April 2002.

9. S. J. Pawel, D. W. Townley, D. E. Roy, and D. F. Wilson, Correlation of Process Data and Electrochemical Noise to Assess Kraft Digester Corrosion: Spring Grove Experiment, Oak Ridge National Laboratory Technical Memo ORNL/TM-2003/107, April 2003.

10. S. J. Pawel, D. W. Townley, D. E. Roy, and D. F. Wilson, Correlation of Process Data and Electrochemical Noise to Assess Kraft Digester Corrosion: Second Year at Spring Grove, Oak Ridge National Laboratory Technical Memo ORNL/TM-2004/42, expected April 2004.

11. The Silver/Silver Sulfide Reference Electrode for Use in Corrosion Studies in Kraft White Liquor, The Institute of Paper Chemistry, Project 3556, Report One, February 15, 1984.

12. D. C. Crowe and D. Tromans, "The Silver Sulfide Reference Electrode for Use in Alkaline Sulfide Solutions," Corrosion, Vol. 42, No. 7 (1986) p. 409. 
13. P. M. Singh, principle investigator; unpublished research at the Institute of Pulp and Paper Science (Atlanta, GA) January 2003, results reported in detail to project advisors at Team Meeting July 2003.

14. H. MacLean and J. A. F. Gardner, "Heartwood Extractives in Digester Corrosion," Pulp and Paper Magazine of Canada, p.125, November 1953.

15. P. M. Singh, et. al., "Corrosivity of Black Liquors - Role of Wood Species Pulped," $10^{\text {th }}$ International Symposium on Corrosion in the Pulp and Paper Industry, EFC Event \#249, Helsinki, Finland, August 2001, pp. 409-425.

16. G. E. Giles, Wood Pulp Digester Wall Corrosion Investigation, Oak Ridge National Laboratory Technical Memo ORNL/TM-2003/206, August 2003.

17. D. W. Townley, S. J. Pawel, D. F. Wilson, and D. E. Roy, "Investigation of the use of Electrochemical Noise to Monitor Corrosion in Kraft Pulp Digesters," Corrosion 2003 Paper \#03411, National Association of Corrosion Engineers (NACE International), March 2003. 


\section{INTERNAL DISTRIBUTION}

\begin{abstract}
1. E. E. Bloom
2. L. L. Horton

3. J. R. Keiser

4-8. S. J. Pawel
\end{abstract}

9. P. F. Tortorelli

10. D. F. Wilson

11. Central Research Library

12. ORNL Laboratory Records-RC 
